\title{
A Racionalizaçáo das Tradiçóes na Modernidade: o Diálogo Entre Anthony Giddens e JÜrgen Habermas
}

\author{
Caroline Kraus Luvizotto ${ }^{I}$
}

\begin{abstract}
RESUMO: Partindo das reflexôes de Habermas e sua concepção de modernidade, compreendida como um projeto inacabado, Giddens salienta que, em todas as sociedades, a manutençâo da identidade pessoal e sua conexão com identidades sociais mais amplas é um requisito primordial para a segurança ontológica. Para alcançar a segurança ontológica, a modernidade teve que (re)inventar tradiçôes e se afastar de "tradiçóes genuínas", isto é, aqueles valores radicalmente vinculados ao passado prémoderno. Este é um caráter de descontinuidade da modernidade - a separação entre o que se apresenta como o novo e o que persiste como herança do velho. É sobre a relação entre tradiçáo e modernidade e sobre um diálogo entre Giddens e Habermas que trata este texto. O objetivo é identificar os pontos de contato e as diferenças das teses defendidas por ambos, a fim de avaliar as contribuiçóes de cada um para se pensar a racionalizaçáo das sociedades contemporâneas. A modernidade tardia ou reflexiva é um processo de mudanças ininterruptas que afetam as bases da sociedade ocidental. Frente a uma realidade em constante alteração, faz-se necessário escolher entre uma certeza do passado e uma nova realidade, em contínua mutação. Nesse sentido, e segundo a perspectiva habermasiana, o caráter reflexivo da modernidade está nesse processo de escolha entre as certezas herdadas do passado e as novas formas sociais que conduz à reflexão ou, até mesmo, à reformulação das práticas sociais, provocando a racionalização e a (re)invençấo de diversos aspectos da vida em sociedade.
\end{abstract}

PALAVRAS-CHAVE: Anthony Giddens. Jürgen Habermas. Modernidade. Tradição.

As sociedades modernas encontram-se em um momento em que são obrigadas a refletir sobre si mesmas e, ao mesmo tempo, desenvolver a capacidade de refletir retrospectivamente sobre si mesmas, caracterizando a chamada modernização reflexiva.

\footnotetext{
${ }^{1}$ Doutora em Ciências Sociais pela FFC/UNESP-Marília. Docente do Mestrado em Educação e do Mestrado em Meio Ambiente e Desenvolvimento Regional da Universidade do Oeste Paulista, Unoeste.E-mail: carol.luvizotto@hotmail.com.
} 
Ao refletir a respeito da origem da modernidade, Habermas a associa ao surgimento de uma consciência temporal que confronta o moderno ao antigo e cria uma concepção histórica processual da vida, cujo horizonte é um futuro que não pode ser previsto. Para o autor, a modernidade é um projeto inacabado, no qual o indivíduo deve aprender com os desacertos que acompanham o projeto (HABERMAS, 1992).

A Teoria da Modernidade de Habermas integra a Teoria da Ação Comunicativa. Essa teoria procura explicar a origem da moderna sociedade ocidental, diagnosticar seus problemas e propor correção. Para tal, baseia-se em um conceito de sociedade que associa a perspectiva subjetiva do mundo vivido à perspectiva objetiva e do resgate de um conceito de racionalidade.

Pode-se assim entender a modernidade como o fracionamento dos modelos estabelecidos no passado, construídos em unidades fechadas e que agora se abrem direcionadas ao desconhecido. Pode ser encarada como a emancipação da razão ou a forma de (re)inventar novos caminhos de pensamento que deem conta dos novos questionamentos. Sáo as novas leituras de mundo.

Partindo das colocaçóes de Habermas e de seu projeto de modernidade, no qual esta é compreendida como um projeto inacabado, Giddens salienta que, em todas as sociedades, a manutenção da identidade pessoal e sua conexão com identidades sociais mais amplas constituem requisito primordial para a segurança ontológica. A modernidade, para alcançar a segurança ontológica, teve que (re)inventar tradiçóes e se afastar de "tradiçóes genuínas", isto é, aqueles valores radicalmente vinculados ao passado pré-moderno. Este é um caráter de descontinuidade da modernidade - a separação entre o que se apresenta como o novo e o que persiste como herança do velho.

Ao indivíduo moderno cabe confrontar seus exageros, assumir-se como objeto de reflexão e exercer uma crítica racional sobre o próprio sistema, tornando-se um tema e um problema para si mesmo. Esse indivíduo reflete sobre o mundo em que vive e exerce uma análise racional das consequências de fatos passados, das condiçóes atuais e da probabilidade de perigos futuros, procurando assim minimizar os perigos, à medida que esse futuro vai se tornando presente.

É sobre a relação entre tradição e modernidade e sobre um diálogo entre Giddens e Habermas que trata este texto. 


\title{
Habermas, Modernidade e a Racionalização da Sociedade
}

Em Ciência e política: duas vocaçôes, Max Weber (1968) definiu o advento da modernidade como um processo crescente de racionalizaçáo intelectualista, que estava ligado intimamente ao desenvolvimento científico. Habermas (1992) comenta Weber, no seu texto Modernidade: um projeto inacabado:

\begin{abstract}
Max Weber caracterizou a modernidade cultural, mostrando que a razão substancial expressa em imagens de mundo religiosas e metafísicas se divide em três momentos, os quais apenas formalmente ainda podem ser mantidos juntos. Uma vez que as imagens de mundo se desagregam e os problemas legados se cindem entre os pontos de vista específicos da verdade, da justeza normativa, da autenticidade ou do belo, podendo ser tratados, respectivamente como questão de conhecimento, como questão de justiça e como questáo de gosto, ocorre nos tempos modernos uma diferenciação de esferas de valor: ciência, moral e arte. (HABERMAS, 1992, p. 109-110).
\end{abstract}

De acordo com Habermas, Weber concebe a modernidade como o próprio mundo racionalizado da economia capitalista, das esferas de valor, do Estado burocrático moderno, da arte, da moral e da ciência. Além disso, esse mundo racionalizado é definido pela formação de uma estrutura baseada na conduta de vida metódico-racional, sendo um fenômeno típico do Ocidente. Consoante a isso, Anthony Giddens aponta que a modernidade "[...] referese a estilo, costume de vida ou organizaçáo social que emergiram na Europa a partir do século XVII, e que ulteriormente se tornaram mais ou menos mundiais em sua influência" (GIDDENS, 1991, p.11).

Nesse processo, além do modo de vida e formas de organização, também a ciência e a técnica são transformadas na principal força produtiva no campo do agir, comandado pelo desenvolvimento das forças produtivas. Conforme Habermas (1990), umas das consequências desse processo é a colonização do mundo da vida pela razão instrumental, uma racionalidade, que, embora não definida como instrumental, já no início do século passado foi observada por Max Weber (1983) como a "[...] gênese do agir dos indivíduos remetidos ao destino social, ao tributar à razão e liberdade a possibilidade de transformação da sociedade".

Pensando nesse contexto, chega-se ao mundo objetivo de Habermas (1987, p. 30): “[...] o mundo apenas cobra objetividade em virtude de 
ser reconhecido e considerado como único e o mesmo mundo por uma comunidade de sujeitos capazes de linguagem e ação". Isso representa a condição para que os indivíduos possam se entender por meio de uma açáo comunicativa intersubjetiva, refletindo sobre o que acontece no mundo ou o que há de acontecer no mundo.

Habermas ressalta o que ele chama de projeto da modernidade e que tem sido discutido nos dias de hoje. Segundo Harvey, mesmo sendo o termo moderno utilizado há tempos, o que Habermas chama de projeto da modernidade começou a vigorar durante o século XVIII. Harvey salienta que esse projeto corresponde a um grande esforço intelectual dos pensadores iluministas "[...] para desenvolver a ciência objetiva, a moralidade e a lei universais, a arte autônoma nos termos da própria lógica interna destas", objetivando a emancipação humana a partir do acúmulo de conhecimento gerado por muitas pessoas trabalhando livre e criativamente (HARVEY, 1992, p. 23).

Para Habermas, a origem da modernidade está relacionada ao surgimento de uma consciência temporal. $\mathrm{O}$ moderno e o antigo são confrontados e ocorre o fracionamento dos modelos estabelecidos no passado e que, neste momento, se direcionam para um horizonte que não pode ser previsto, um futuro desconhecido. É o momento da emancipação da razão, na qual se criam e (re)inventam-se novas maneiras de encarar os questionamentos da vida atual. São as novas leituras de mundo.

Diante das inúmeras forças de desintegração que estão dentro e fora das sociedades nacionais, destaca-se o fato de que todas as sociedades estão inseridas em uma comunidade de riscos partilhados percebidos como desafios para a ação política cooperativa (HABERMAS, 1995). Os indivíduos só poderão conter o avanço desses riscos se estiverem munidos de uma formação discursiva da opiniáo e da vontade, objetivando a racionalização do mundo da vida. Nesse contexto, a racionalidade é encarada como uma força produtiva importante para os desafios da modernização reflexiva (HABERMAS, 2001).

Em relação à imprevisibilidade, sabe-se que o mundo de hoje é tão previsível quanto era antes. Entretanto, atualmente, ocorrem situações de risco que as geraçóes passadas náo tiveram que enfrentar. A ciência e a tecnologia são as responsáveis pelo surgimento desses novos riscos, que incluem desde os nossos corpos até as grandes mudanças na estrutura da sociedade. Sendo assim, não há como escapar da imprevisibilidade que integra o mundo em que vivemos. Essa imprevisibilidade é estrutural também no sentido de que um 
retorno ao passado não é concebível. A solução para esse impasse é encontrar um novo tipo de equilíbrio entre o risco e a segurança.

Uma consequência da incerteza, da imprevisibilidade, é a individualização, que passa a ser sofrida pelas pessoas que se encontram cada vez mais longe das instituiçôes que davam segurança à sociedade industrial, como, por exemplo, a família. Esse processo de individualização obriga as pessoas a tomarem decisóes cotidianas que implicam risco pessoal e fazem surgir uma infinidade de opinióes sobre os mais variados assuntos, tornando a Sociedade de Risco uma sociedade autocrítica.

Esse contexto, segundo Giddens, deu origem à Modernização Reflexiva, um processo contínuo, imperceptível, quase autônomo, de mudança que atinge as bases da sociedade industrial. Uma das principais características da modernização reflexiva é a racionalização das relaçôes, experiências e tradiçóes.

De acordo com Habermas, a racionalização da sociedade relaciona-se ao processo de institucionalização do progresso científico e técnico. A ciência e a técnica são inseridas nas instituiçôes, transformando-as em sua legitimação, proporcionando uma nova imagem de mundo que orienta a ação.

Todavia, para Habermas, essas mudanças não colocam em xeque a autoridade das tradiçóes culturais que legitimam a dominação. Ou seja, ainda não está concluído o processo de racionalização. "As sociedades tradicionais são aquelas cujos subsistemas de agir racional-com-respeito-a-fins é contido nos limites da legitimação das tradiçôes culturais" (HABERMAS, 1983, p. 323).

De modo geral, a racionalização é, para Habermas, um modo de compreender a transição de uma sociedade tradicional para uma sociedade moderna, por meio da mudança de seus quadros institucionais. A racionalização é um reflexo do progresso técnico-científico sobre o contexto institucional.

No que concerne às sociedades tradicionais, Habermas (1983) afirma que são sociedades em oposição aos sistemas sociais primitivos, o que acontece principalmente em três pontos:

1. A existência de um poder central estatal de dominação que se encontra em oposição ao poder tribal;

2. A divisão da sociedade em classes, em oposição às relaçóes de parentesco;

3. A existência de uma imagem mítica ou religiosa para a legitimação do poder. 
As sociedades modernas, entretanto, constituem-se sobre o fundamento de uma técnica razoavelmente e relativamente desenvolvida e sobre uma divisão do trabalho social que não se sustenta sob a ótica do parentesco (HABERMAS, 1983).

Nas sociedades modernas, segundo Habermas, a tradição desenvolve uma função quase transcendental, uma vez que articula antecipadamente as conexóes dos mundos objetivo, social e subjetivo, revelando e possibilitando horizontes de interpretaçôes. O mundo da vida, para Habermas, é o horizonte de significaçáo no qual os indivíduos se movimentam, de modo que toda situação, mesmo a nova, de qualquer origem, não se encontra num vazio de significado: será sempre pré-interpretada no contexto de uma dada tradição.

Enfatiza Luchi (1999, p. 275):

Novas situações são vinculadas ao mundo já existente, na dimensão semântica, de tal modo a assegurar a continuidade das tradiçóes e a coerência do saber bem como a identidade do grupo. Continuidade e coerência têm como critério a racionalidade do saber válido. Perturbaçóes nesse nível da reprodução cultural do mundo da vida manifestam-se como perda de sentido. A reserva de interpretaçóes não é mais suficiente para o entendimento. Em conseqüência ocorrem também crises de legitimação (âmbito normativo) e de orientaçóes (âmbito subjetivo).

Em sua leitura sobre Habermas, Luchi (1999) salienta que essas novas situaçôes são vinculadas ao mundo já existente, no âmbito social, o que possibilita assegurar a coordenação de ações através de normas legítimas, fortalecendo assim a identidade grupal. O critério para essa estabilidade é a solidariedade dos membros do grupo.

É o modelo de sociedade moderna de Habermas, em seu projeto inacabado, que dá a Giddens elementos para criar a sua teoria sobre modernização reflexiva, conceito essencial para o estudo da racionalização das tradiçóes.

\section{A Modernização Reflexiva ou Modernidade Tardia de Anthony Giddens}

Conjugando o pensamento de Habermas e concebendo as sociedades modernas num estado de alta ou radicalizada modernidade, que apresenta como característica dominante um elevado grau de reflexividade, Giddens (1997) prefere 
a expressão modernidade reflexiva ou tardia, pois acredita que a modernização reflexiva possibilita o entendimento e a criação de interpretaçóes que possam responder às descontinuidades da modernidade, geradas a partir das mudanças da vida moderna. $\mathrm{O}$ autor entende que esse processo favorece o potencial destrutivo envolvido na relação dos homens com a natureza e dos homens entre eles mesmos, aumentando o nível de perigo vivenciado na vida coletiva.

De acordo com Beck, em obra conjunta com Giddens (1997), a sociedade passa a ser reflexiva quando ela se torna um tema e um problema para si própria. As sociedades reflexivas precisam encontrar soluçóes por elas mesmas para os problemas criados sistematicamente pela modernização social, principalmente no âmbito político.

Uma sociedade dotada de reflexividade é marcada pela redescoberta e pela dissoluçáo da tradição, bem como pela destruição daquilo que sempre pareceu ser uma tendência estabelecida. Isso não significa que o mundo se torne imune às tentativas humanas de controle. Essas tentativas de controle, sobretudo no que diz respeito aos riscos de grandes consequências, permanecem necessárias. No entanto, é necessário reconhecer que essas tentativas estarão sujeitas a muitas rupturas.

Pode-se, por conseguinte, abordar a questão do risco. Escreve Beck:

Qualquer um que conceba a modernização como um processo de inovação autônoma deve contar até mesmo com a obsolescência da sociedade industrial. $\mathrm{O}$ outro lado dessa obsolescência é a emergência da sociedade de risco. Este conceito designa uma fase no desenvolvimento da sociedade moderna, em que os riscos sociais, políticos, econômicos e individuais tendem cada vez mais a escapar das instituiçóes para o controle e a proteção da sociedade industrial. (BECK, 1997, p.15).

Beck completa esse pensamento, afirmando que a sociedade de riscos não é uma opçáo a ser escolhida ou rejeitada no calor das lutas políticas. Ela surge no decorrer dos processos de modernização autônoma, os quais produzem ameaças que questionam e destroem as bases da sociedade industrial.

Habermas (1990) acredita que a reflexividade criada pela coletividade deve ser uma reflexividade substancialmente política e deve estar fundamentada num modelo ético universalista. Sublinha Beck (1997): 
O conceito de política na modernidade simples é baseado em um sistema de eixos, em que uma coordenadora passa entre os pólos da esquerda e da direita e a outra, entre o público e o privado. Nesse caso tornar-se político significa deixar a esfera privada e caminhar em direção a esfera pública, ou, ao contrário, permitir que as exigências dos partidos, da política partidária ou do governo proliferem em todos os nichos da vida privada. Se o cidadão não vai para a política, a política vem para o cidadão. (BECK, 1997, p. 60).

$\mathrm{Na}$ visão de Beck (1997), a modernização reflexiva necessita de uma reforma da racionalidade, uma vez que a racionalidade da ciência, com seus padróes e métodos explicativos, não é capaz de controlar o fluxo contínuo de novas ameaças e riscos, vivenciados nas sociedades atuais.

Por consequência, o autor pensa que a racionalidade científica deve ser substituída por uma ética reflexiva, baseada na evidência de que "[...] o microcosmo da conduta da vida pessoal está inter-relacionado com o macrocosmo dos problemas globais, terrivelmente insolúveis" (BECK, 1997, p. 61). Ademais, as sociedades modernas encontram-se em um momento em que são obrigadas a refletir sobre si mesmas e, ao mesmo tempo, desenvolvem a capacidade de refletir retrospectivamente sobre si mesmas, caracterizando a chamada modernização reflexiva ou a modernidade tardia, para Giddens (1997).

Nesse contexto, o conhecimento científico vem substituindo a tradição, na busca dos indivíduos por fontes de segurança. $\mathrm{O}$ mecanismo que enfrenta a insegurança produzida pelas transformaçóes sociais e a ruptura das estruturas tradicionais é a absorção de sistemas abstratos de conhecimentos, que são teorias, conceitos e descobertas e, conforme Giddens, "[...] em todas as sociedades, a manutenção da identidade pessoal, e sua conexão com identidades sociais mais amplas, é um requisito primordial de segurança

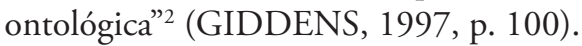

O autor observa que vivemos uma época na qual estão presentes, de modo muito marcante, a desorientação e a sensação de que não compreendemos completamente os eventos sociais e que, consequentemente, perdemos o controle. Entre as mudanças trazidas pela modernidade, evidenciam-se a

\footnotetext{
${ }^{2}$ Giddens refere-se à segurança ontológica como um sentido de ordem e continuidade a respeito das experiências do indivíduo. Argumenta que isso é dependente da habilidade da pessoa de dar sentido à sua vida, um significado que é achado em experimentar emoçóes estáveis positivas e por evitar o caos e a ansiedade
} 
transformação das relaçóes sociais e a percepção dos indivíduos e coletividades sobre os perigos e riscos do viver, bem como sobre a segurança e a confiança:

A modernidade, pode-se dizer, rompe o referencial protetor da pequena comunidade e da tradição, substituindo-as por organizaçóes muito maiores e impessoais. $\mathrm{O}$ indivíduo se sente privado e só num mundo em que lhe falta o apoio psicológico e o sentido de segurança oferecidos em ambientes mais tradicionais. (GIDDENS, 2002, p. 38).

A modernidade tardia indica uma mudança no modo de vivenciar as relaçóes, a partir da identificação da razão como o elemento ordenador que produz confiança e elimina ou minimiza os riscos. Ao indivíduo moderno cabe confrontar seus exageros, assumir-se como objeto de reflexão e exercer uma crítica racional sobre o próprio sistema, tornando-se um tema e um problema para si mesmo. Esse indivíduo reflete sobre o mundo em que vive e exerce uma análise racional das consequências de fatos passados, das condiçóes atuais e da probabilidade de perigos futuros, procurando assim minimizar os perigos, à medida que esse futuro vai-se tornando presente.

Esse caráter de descontinuidade, percebido especialmente entre as ordens sociais tradicionais e as instituiçóes sociais modernas, tem como principais características o ritmo de mudança, que a modernidade coloca em movimento, o escopo da mudança, isto é, a sua abrangência global, e a natureza das instituiçóes modernas.

Giddens (1991) afirma que uma importante característica da modernidade tardia é o seu dinamismo, derivado de três fontes dominantes: a separação entre tempo espaço, o desenvolvimento de mecanismos de desencaixe e a apropriação reflexiva do conhecimento.

No que concerne à separação entre tempo e espaço, pode-se afirmar que esta provoca as relaçóes entre indivíduos, grupos ou instituiçóes ausentes, em que "[...] os locais são completamente penetrados e moldados em termos de influências sociais bem distantes deles" (GIDDENS, 1991, p. 22). A separação entre tempo e espaço é a principal condição para o processo de desencaixe das instituiçôes sociais; com efeito, desencaixe, para ele, é " [...] o deslocamento das relações sociais de contextos locais de interação e sua reestruturação através de extensōes indefinidas de tempo-espaço" (GIDDENS, 1991, p. 24). O autor distingue dois tipos de mecanismos de desencaixe ligados ao desenvolvimento das instituiçôes sociais modernas: as fichas simbólicas e os sistemas peritos. 
Por fichas simbólicas quero significar meios de intercâmbio que podem ser "circulados" sem ter em vista as características específicas dos indivíduos ou grupos que lidam com eles em qualquer conjuntura particular. Vários tipos de fichas simbólicas podem ser distinguidos, tais como os meios de legitimação política; devo me concentrar aqui na ficha do dinheiro. (GIDDENS, 1991, p. 25).

Os sistemas peritos estão presentes em todos os aspectos da vida social, nas condiçóes de modernidade e, segundo o autor, são mecanismos de desencaixe porque

[o]s sistemas peritos são mecanismos de desencaixe porque, em comum com as fichas simbólicas, eles removem as relaçôes sociais das imediaçôes do contexto. Ambos os tipos de mecanismo de desencaixe pressupóem, embora também promovam, a separação entre tempo e espaço como condição do distanciamento tempo-espaço que eles realizam. Um sistema perito desencaixa da mesma forma que uma ficha simbólica, fornecendo "garantias" de expectativas através de tempo-espaço distanciados. Este "alongamento" de sistemas sociais é conseguido por meio da natureza impessoal de testes aplicados para avaliar o conhecimento técnico e pela crítica pública (sobre a qual se baseia a produção do conhecimento técnico), usado para controlar sua forma. (GIDDENS, 1991, p. 31).

A terceira fonte dominante que atribui à modernidade um caráter de dinamismo é a apropriação reflexiva do conhecimento. Para Giddens (1991, p. 51), "[...] a produção de conhecimento sistemático sobre a vida social tornase integrante da reprodução do sistema, deslocando a vida social da fixidez da tradição".

Pensando em conjunto essas três características, o autor resume:

Tomadas em conjunto, estas três características das instituições modernas ajudam a explicar por que viver no mundo moderno é mais semelhante a estar a bordo de um carro de Jagrená ${ }^{3}$ em disparada [...] do que estar num automóvel a motor cuidadosamente controlado e bem dirigido. A apropriação reflexiva do conhecimento, que é intrinsecamente energizante mas também necessariamente instável, se amplia para incorporar grandes extensóes de tempo-espaço. Os mecanismos de desencaixe fornecem os

\footnotetext{
${ }^{3}$ Ressalta Giddens (1991, p. 118): "O termo vem do hindu Jagannalh, "senhor do mundo", e é um titulo de Krishna; um ídolo desta deidade era levado anualmente pelas ruas num grande carro, sob cuja rodas, conta-se, atiravam-se seus seguidores para serem esmagados".
} 
meios desta extensão retirando as relaçóes sociais de sua "situacionalidade" em locais específicos. (GIDDENS, 1991, p. 51-52).

Posto isso e direcionando o foco para o indivíduo, no cenário da modernidade, faz-se necessário tecer consideraçôes sobre a questão da identidade.

Giddens (2002) assevera que, nas sociedades tradicionais, é a tradição, o parentesco e a localidade que limitam a identidade social dos indivíduos. $\mathrm{Na}$ sociedade moderna, caracterizada como uma ordem pós-tradicional, que rompe com as práticas e preceitos preestabelecidos, pode-se identificar a ênfase ao cultivo das potencialidades individuais, possibilitando ao indivíduo uma identidade móvel, mutável. Nesse sentido, segundo Dias (2005, p. 87),

[...] na modernidade, o "eu" torna-se, cada vez mais, um projeto reflexivo, pois aonde náo existe mais a referência da tradição, descortina-se, para o indivíduo, um mundo de diversidade, de possibilidades abertas, de escolhas. O indivíduo passa a ser responsável por si mesmo e o planejamento estratégico da vida assume especial importância.

Sem dúvida, uma grande característica desse projeto reflexivo é estar relacionado a um mundo cada vez mais constituído de informação e procurar negar modos pré-estabelecidos de conduta, conduzindo o indivíduo a realizar escolhas sucessivas, permitindo que este componha a sua narrativa de identidade, sempre aberta a revisóes. Para Giddens (1991, p. 39), “[...] a reflexividade da vida social moderna consiste no fato de que as práticas sociais são constantemente examinadas e reformadas à luz de informação renovada sobre estas próprias práticas, alterando assim constitutivamente seu caráter”.

Em relação ao caráter de reflexividade da modernidade tardia, Dias (2005, p. 87) afirma:

Nas condiçôes da alta modernidade, sensaçóes de inquietude e ansiedade podem se infiltrar na experiência cotidiana dos indivíduos, pois a narrativa da auto-identidade torna-se inerentemente frágil diante das intensas e extensas mudanças que a modernizaçáo provoca. Entretanto, ainda que a modernidade seja inerentemente suscetível à crise, favorece, por outro lado, a apropriação de novas possibilidades de ação ao indivíduo, oferecendo oportunidades de revisão de hábitos e costumes tipicamente tradicionais. 
Giddens (2002) considera a reflexividade da modernidade uma das maiores influências sobre o dinamismo das instituiçôes modernas. É essa reflexividade que permite compreender de que forma a modernidade altera a natureza da vida social cotidiana. No caso específico das tradiçóes, a modernidade tardia é fundamental para a compreensão da racionalização das tradiçôes, nas sociedades modernas.

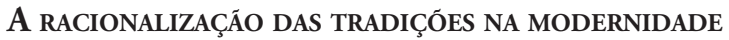

A modernidade tardia ou reflexiva é um processo de mudanças ininterruptas que afetam as bases da sociedade ocidental. Frente a uma realidade em constante alteração, é preciso escolher entre uma certeza do passado e uma nova realidade, em constante mutação. Em decorrência - e segundo a perspectiva habermasiana -, o caráter reflexivo da modernidade está nesse processo de escolha entre as certezas herdadas do passado e as novas formas sociais, o qual que conduz à reflexão ou, até mesmo, à reformulação das práticas sociais, provocando a racionalização e a (re)invenção de diversos aspectos da vida em sociedade.

A tradição passa por esse processo de racionalização (GIDDENS, 1997, 2002). Isso significa dizer que os conceitos e categorias relacionados à tradição são produzidos pelos atores sociais com o objetivo de atender às expectativas de suas próprias ações e à necessidade de relaçóes significativas, em suas vidas.

No contexto da modernização reflexiva, as tradiçóes são racionalizadas e (re)inventadas, e os símbolos, as suposiçôes, as práticas, os preconceitos, as normas, as crenças e padróes de comportamento são(ditos) trazidos do passado, atuando como materiais simbólicos necessários para a autoformação da identidade individual e coletiva. A tradição molda o sentido que cada indivíduo tem de si mesmo e de pertencer a um grupo social. Evidentemente, à medida que os indivíduos ingressam em grupos sociais e conhecem os espaços construídos pela coletividade e pelas interaçóes sociais vivenciadas por seus membros, passam a habituar-se a seus códigos e à sua sociabilidade. Para Habermas, essa solidariedade e autorreconhecimento é que mantêm a estabilidade do grupo.

A (re)invenção das tradiçôes é outro indício do processo de racionalização das tradiçôes, na modernidade tardia. É possível criar, inventar, reinventar tradiçóes e conferir-lhes a aparência de repetição. Consequentemente, símbolos, 
mitos de origem, percursos históricos, identidades, entre muitos outros elementos, podem ser criados e recordados, interpretados em permanência, atribuindo um caráter de continuidade, segurança e estabilidade à tradição.

As tradiçóes (re)inventadas baseiam-se na referência a um passado histórico e caracterizam-se por estabelecer com ele uma continuidade artificial, na medida em que são reações a situaçóes novas impostas a sociedade. Assumem a forma de referência a situaçóes anteriores, por meio da repetição quase que obrigatória de práticas, símbolos, crenças, entre outros.

A racionalização das tradiçóes, nesse contexto de modernidade apontado por Habermas e Giddens, evidencia que a sociedade atual está vivendo uma fase de modernização reflexiva.

LUVIZOTTO, Caroline Kraus. The rationalization of traditions in modernity: the dialogue between Anthony Giddens and Jürgen Habermas. Trans/Form/Ação, Marília, v. 36, p. 245-258, 2013. Edição Especial.

\begin{abstract}
Based on the reflections of Habermas and his conception of modernity, understood as an unfinished project, Giddens stresses that in all societies the maintenance of personal identity and its connection to broader social identities is a primordial requirement for ontological security. To achieve ontological security, modernity had to (re) invent traditions and get away from "genuine traditions", that is, those values radically linked to the pre-modern past. This is a character of the discontinuity of modernity, the separation between what is presented as the new and that which persists as the legacy of the old. This article discusses the relationship between tradition and modernity and the dialogue between Giddens and Habermas. The goal is to identify the points of contact and the differences in the theses defended by both authors, in order to assess their contributions to discussions of the rationalization of contemporary societies. Late or reflexive modernity is an uninterrupted process of changes that affect the foundations of Western society. Faced with a reality of constant change, it is necessary to choose between the certainty of the past and a new reality of continuous change. In this sense, and according to the Habermasian perspective, the reflexive character of modernity is found in this process of choosing between the certainties inherited from the past and new social forms, a process that that leads to the reflection on - or even the recasting of - social practices, causing the rationalization and (re) invention of various aspects of life in society.
\end{abstract}

KEYWORDS: Anthony Giddens. Jürgen Habermas. Modernity. Tradition. 


\section{REFERÊNCIAS}

BECK, U. A Reinvenção da Política: Rumo a uma Teoria da Modernização Reflexiva. In: BECK, U.; GIDDENS, A.; LASH, S. Modernização Reflexiva. Sáo Paulo: Editora da Universidade Estadual Paulista, 1997.

DIAS, R. C. P. Modernidade e Identidade. Resenha. Psicologia \& Sociedade, 17, n. 3, 8081; set/dez: 2005.

GIDDENS, A. Risco, confiança e reflexividade. In: BECK, U.; GIDDENS, A.; LASH, S. Modernização Reflexiva. São Paulo: Editora da Universidade Estadual Paulista, 1997. . Modernidade e Identidade. Rio de Janeiro: Jorge Zahar, 2002.

. As Consequências da Modernidade. São Paulo: Editora da Universidade Estadual Paulista, 1991.

HABERMAS, J. Teoría de la Acción Comunicativa. Madrid: Taurus, 1987.

Modernidade - um projeto inacabado. In: ARANTES, O.; ARANTES, P. Um ponto cego no projeto moderno de Jürgen Habermas. São Paulo: Brasiliense, 1992.

. O Estado-nação europeu frente aos desafios da globalização. Novos Estudos. São Paulo, n 43 . nov./1995.

. O discurso filosófico da modernidade. Lisboa: Publicaçōes Dom Quixote, 1990.

. A Constelação pós-nacional: ensaios políticos. São Paulo: Littera Mundi, 2001.

. A inclusão do outro. Sáo Paulo: Loyola, 2002.

. Técnica e Ciência enquanto Ideologia. Tradução de Zeljko Loparic e Andréa Maria Altino de Campos Loparic. São Paulo: Abril Cultural, 1983 (Coleção Os Pensadores).

LUCHI, P. J. A superaçâa da Filosofia da Consciência em Habermas: a questâo do sujeito na formação da teoria comunicativa da sociedade. Roma: Editrice Pontifícia Università Gregoriana, 1999.

WEBER, M. Ciência e Politica. Duas vocaçóes. São Paulo: Cultrix, 1968. . A Ética Protestante e o espirito do capitalismo. São Paulo: Pioneira, 1983. 